From the Department of Pharmacology, University of Nijmegen, Nijmegen, Holland

\title{
Pharmacokinetics of Diazepam in Dogs, Mice and Humans
}

\author{
By \\ Eppo van der Kleijn, Jacques M. van Rossum, Elly T. J. M. Muskens \\ and Nico V. M. Rijntjes
}

Key-words: Pharmacokinetics - diazepam - distribution - metabolism.

Pharmacokinetic equations describing the course of bodyfluid concentrations have been succesfully applied for the design of dosage regimens in e.g. chemotherapy (KrüGer ThIEMER \& BüNGER 1965 \& 1966; DOLUISIO \& DitTeRT 1969) and cardiology (JeLlifFe 1967). They are based on the assumption of a relatively simple relationship between the concentration in the bodyfluid where the drug can be assayed and the concentration in a closely related bodyregion, which is responsible for the pharmacological activity, but where it cannot be sampled. In the case of chemotherapy defined criteria for activity can be used both in vivo and in vitro. Since the clinical criteria for many drugs are vague and subjective, there is a great need for more objective parameters that can be used in accompaning the patients drug treatment. In many cases the kinetic parameters for the use of the regimen calculation are estimated from data after a single dose. However, many individual factors mediate the response and the availibility of the drugs in the bodyfluids.

This paper deals with the single dose, steady state and post steady state kinetics of diazepam and its primary metabolite desmethyldiazepam. Specific and general factors will be discussed that can explain the individual and species differences in pharmacokinetics.

\section{Methods}

Gas chromatographic analyses in plasma of humans and dogs.

Diazepam (valium ${ }^{\otimes}$, abbreviated:D) and its metabolites: desmethyldiazepam (DD), oxydiazepam (OD) and oxydesmethyldiazepam (or oxazepam; serax $\left.{ }^{\circledR}\right)(O)$ can simultaneously and specifically be assayed in bodyfluids at the pharmacological levels using a gas chromatographic method and 69Ni-electroncapture detection (MARCucci et al, 1968; VAN DER KLEIJN, 1969c). 
The minimum level that can quantitatively be assayed is $30 \mathrm{ng} / \mathrm{ml}$ using N-benzyl-5chlor-2-aminobenzophenon, medazepam or griseofulvin as internal standard.

Isotope dilution analyses in dogs.

D was administered intravenously in dogs in a dose of $1 \mathrm{mg} / \mathrm{kg}$ corresponding to $2 \mu \mathrm{ci} /$ $\mathrm{kg}$. In one experiment diazepam labeled with ${ }^{14} \mathrm{C}$ in the $\mathrm{C}_{2}$-position, in a second experiment diazepam labeled in the $\mathrm{N}_{1}-\mathrm{CH}_{3}$-position, was used. Heparinized samples of $20 \mathrm{ml}$ were frequently taken at increasing intervals from a catheter placed in the femoral artery.

$1.0 \mathrm{ml}$ plasma was used for total radioactivity measurement by liquid scintillation counting (Packard, Model 3380 AAA).

$2.0 \mathrm{ml}$ plasma were used for the gas chromatographic analysis of parent diazepam and metabolite (DD). $11 \mathrm{ml}$ of the sample were used for the determination of plasma protein free fraction of total radioactivity.

\section{Autoradiography in mice.}

Distribution of the radioactive drug was studied by means of the whole body autoradiographic method of ULLBERG (1954) using a Jung-K microtome (VAN DER KIEINN 1969c). In this study diazepam- $\mathrm{N}_{1}-14 \mathrm{CH}_{3}$ was used. The specific activity of the compound amounted to $25.7 \mathrm{mg} / \mathrm{mci}$.

$200 \mu \mathrm{ci} \approx 5.1 \mathrm{mg} / \mathrm{kg}$ was administered intravenously in the tail vein. The drug was solubilized in a saline solution containing $2 \%$ polysorbate 80 .

\section{Studies in humans.}

The test subjects were psychiatric patients, who had been exposed to several drugs during their chronic hospitalization. They were examined physically and found healthy. For the sake of this study other drugs were withheld during at least one week prior to the diazepam treatment.

The drug was administered as the commercially available $10 \mathrm{mg}$ tablets at equal intervals of $8 \mathrm{hrs}$ during 15 subsequent days. After this period the drug and metabolite concentrations were followed during the next 4 days.

One patient here reported received a single dose of $30 \mathrm{mg} 24 \mathrm{hrs}$ before the subchronic study, that lasted 13 days and subsequent 3 days.

Samples were taken at increasing intervals after the single dose, and during the post treatment period. During the subchronic study samples were taken 1 hour after the intake of each dose during the first three days and 1 hour after the last dose on the subsequent days.

\section{Plasma protein binding.}

The plasma protein binding capacity has been determined with the preparative ultracentrifugation method as earlier reported (VAN DER KLEIJN 1969) at 70,000 rpm.

\section{Results}

Dogs.

The experiment in dogs are undertaken to enable a more accurate analysis of the kinetic pattern of diazepam in plasma than is technically feasible in humans. 


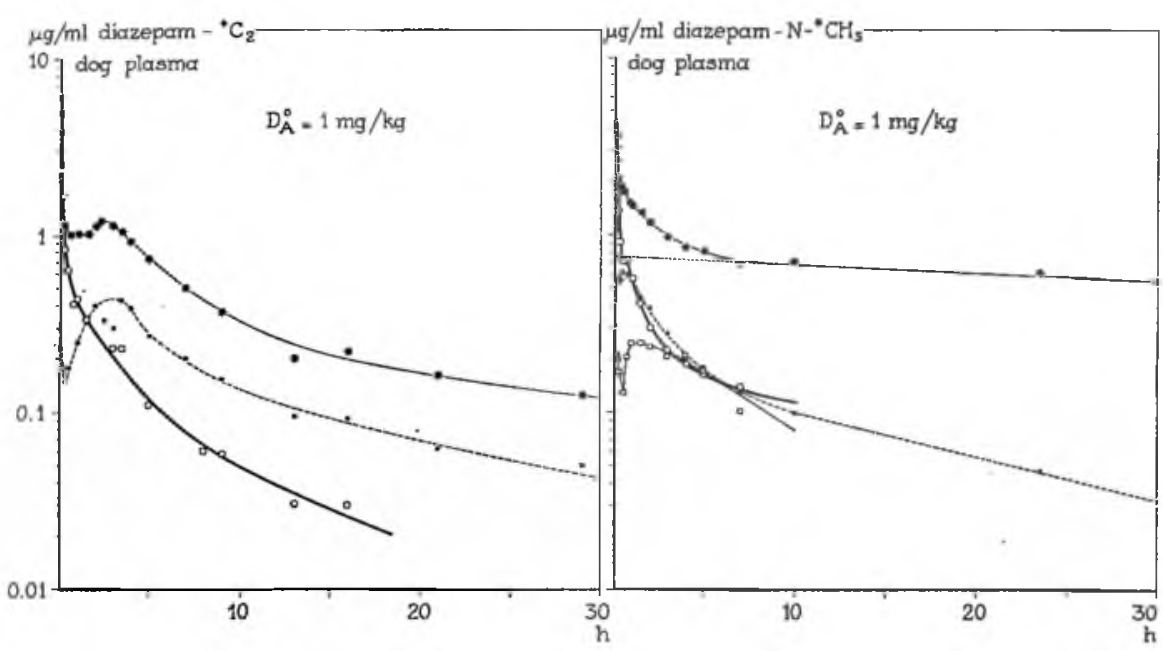

Fig. 1. Concentration-time course of total radioactivity in bloodplasma (*-*), of total

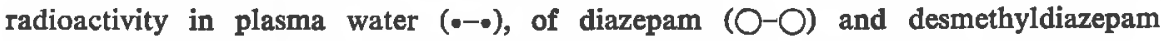
$(\square-\square)$ after rapid intravenous administration of $1 \mathrm{mg}$ diazepam/kg in two dogs.

In fig. 1 it is shown that the elimination of the parent diazepam occurs along at least a triphasic curve. In general the accuracy of the kinetic parameters as they can be derived from concentration-time curves after a single dose depends largely on the accuracy of the last phase of the curve (WAGNER 1969).

Unfortunately it is not possible to determine the drug long enough during this last phase. It can be remarked that using the ${ }^{14} \mathrm{C}_{2}$-labeled compound a shoulder in the curve of the total radioactivity is observed. This is even more pronounced for the total radioactivity in the plasma water.

After the first three hours the protein binding capacity hardly changes anymore, indicating that metabolism has resulted in one or more compounds that show a protein binding capacity of about $58 \%$.

After administration of the $\mathrm{N}^{14} \mathrm{CH}_{3}$-labeled compound the elimination pattern of the total radioactivity is different. The protein binding capacity increases during the time course.

Mice.

Macroautoradiography is a useful technique to study the actual significance of the plasma concentration for the distribution of the drug in the body. It allows a visual localization of the drug in regions where it cannot be detected by sampling techniques. Plasma may poorly reflect the kinetic processes relevant for the pharmacological activity or for distribution of drugs with selective tissue partioning or binding. 
Earlier studies (VAN DER KLEIJN 1969a) using ${ }^{14} \mathrm{C}_{2}$-labeled diazepam demonstrated that although the parent drug is rapidly eliminated, the metabolites are long retained in the body, e.g. in the gastrointestinal tract, the liver and the white matter of the spinal cord and the brain. By using the $\mathrm{N}_{1}{ }^{14} \mathrm{CH}_{3}$-labeled compound it can be confirmed that the parent drug is very rapidly eliminated. No significant excretion of radioactive material into the stomach can be observed in the presented autoradiograms. At short periods after injection a rapid uptake in the adipose tissue is evident. The elimination from the brain proceeds faster than from the bodyfat. The initial uptake in the spinal cord, the gray matter of diencephalon, and cortex is similar to other ataractic drugs. No long retention of material in the white matter can be observed in these mice.

A small amount of radioactive material is excreted into the gall bladder and subsequently into the intestine. The drug shows an initial high affinity for the myocardium. After 1 hour virtually no drug can be observed in tissues other than the excretory organs.

Remarkable is the uptake in bone marrow, salivary glands, lachrymal glands and the skin that can be observed even after $18 \mathrm{hrs}$ following the administration (figs. 2 and 3). The patterns after $4 \mathrm{hrs}$ and later resemble the distribution of radioactivity following the injection of radioactive formaldehyde (HeSPe \& PrINS, personal communication 1969).

\section{Studies in humans.}

In earlier studies (DE SILva et al. 1966; VAN DER KLEIJN 1969c) it was observed that after a single oral dose of diazepam it was not possible to estimate the individual kinetic parameters because of the erratic course of the concentration.

After an initial rapid absorption phase and subsequent rapid decline, a recovery of the level was observed followed by a much slower elimination part. This latter phase, with a half-life longer than the dosage interval, is responsible for accumulation during chronic treatment under the conditions that there are no changes in distribution volume or metabolic capacity. The analytical minimum concentration that could be assayed also did not allow a conclusion regarding the metabolite after one dose.

The observed rise in plasma level was correlated with food intake and will be discussed later. Fig. 4 gives an example of a patient where this recovery of the concentration has not been observed initially and a biphasic elimination curve can be shown after a single dose of $30 \mathrm{mg}$ diazepam. During the subchronic treatment of 3 doses of $10 \mathrm{mg}$ daily, accumulation of both diazepam (D) and desmethyldiazepam (DD) takes place, D reaching a steady state after approximately 4 days and DD reaching it after about 5 days. After the treatment has been stopped both the $\mathrm{D}$ and the DD concen- 
WHOEY BODY AUTORADIOGRAPHY

DIAZEPAM - N ${ }^{-14} \mathrm{CH}_{3}$

i.V.ADMINISTRATION

MICE
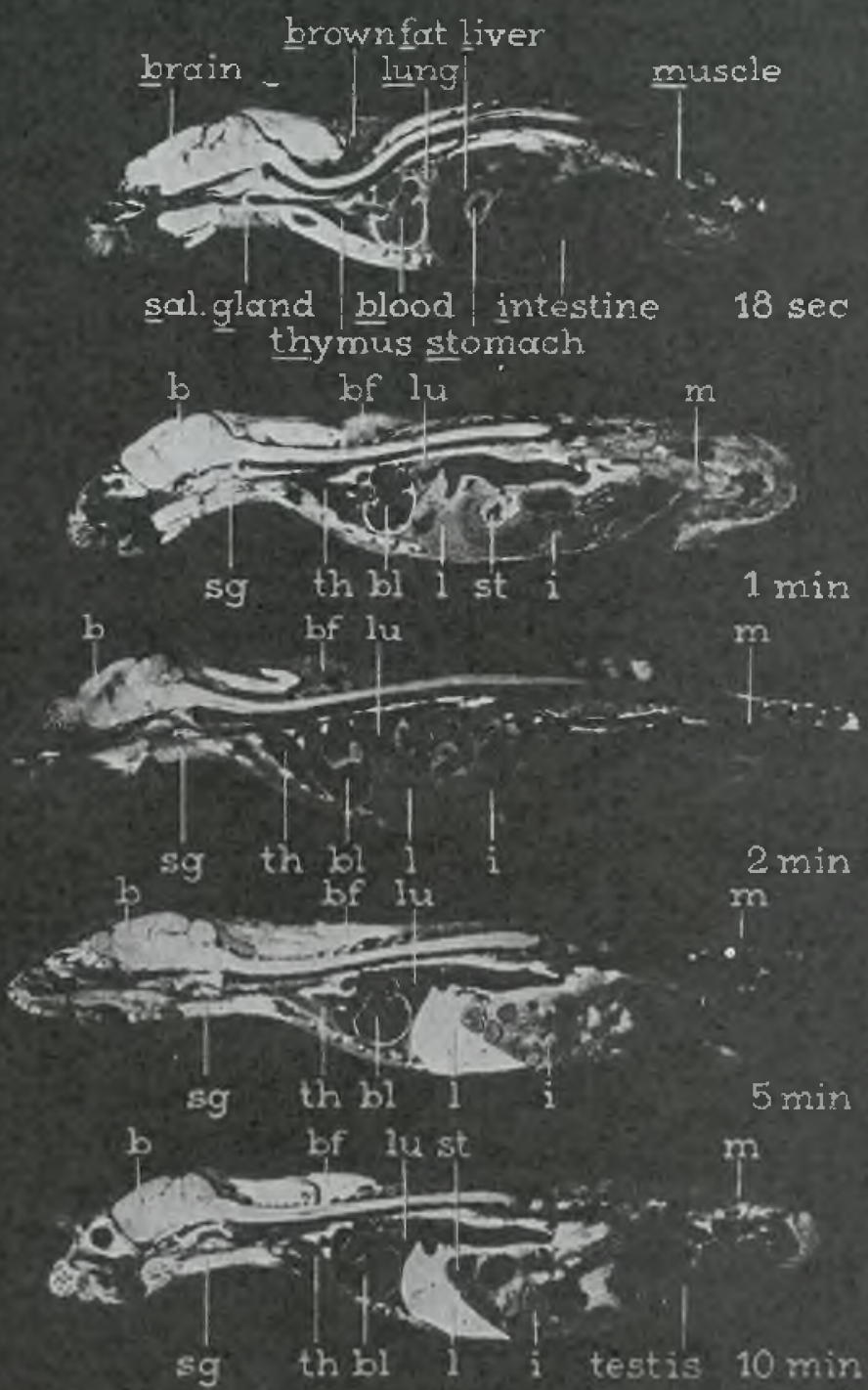

Fig. 2. Autoradiograms of diazepam- $-14 \mathrm{CH}_{3}$ in mice during the first $10 \mathrm{~min}$. after rapid intravenous administration of $5.1 \mathrm{mg} / \mathrm{kg}$. White areas correspond to presence of radioactivity. Notice the rapid disappearance of the radioactivity from the body as compared with earlier autoradiograms using diazepam-14C2 (VAN DER KLEIN 1969). 
WHOLE BODY AUTORADIOGRAPHY DIAZEPAM - N- ${ }^{14} \mathrm{CH}_{3}$ i.V. ADMINISTRATION MICE
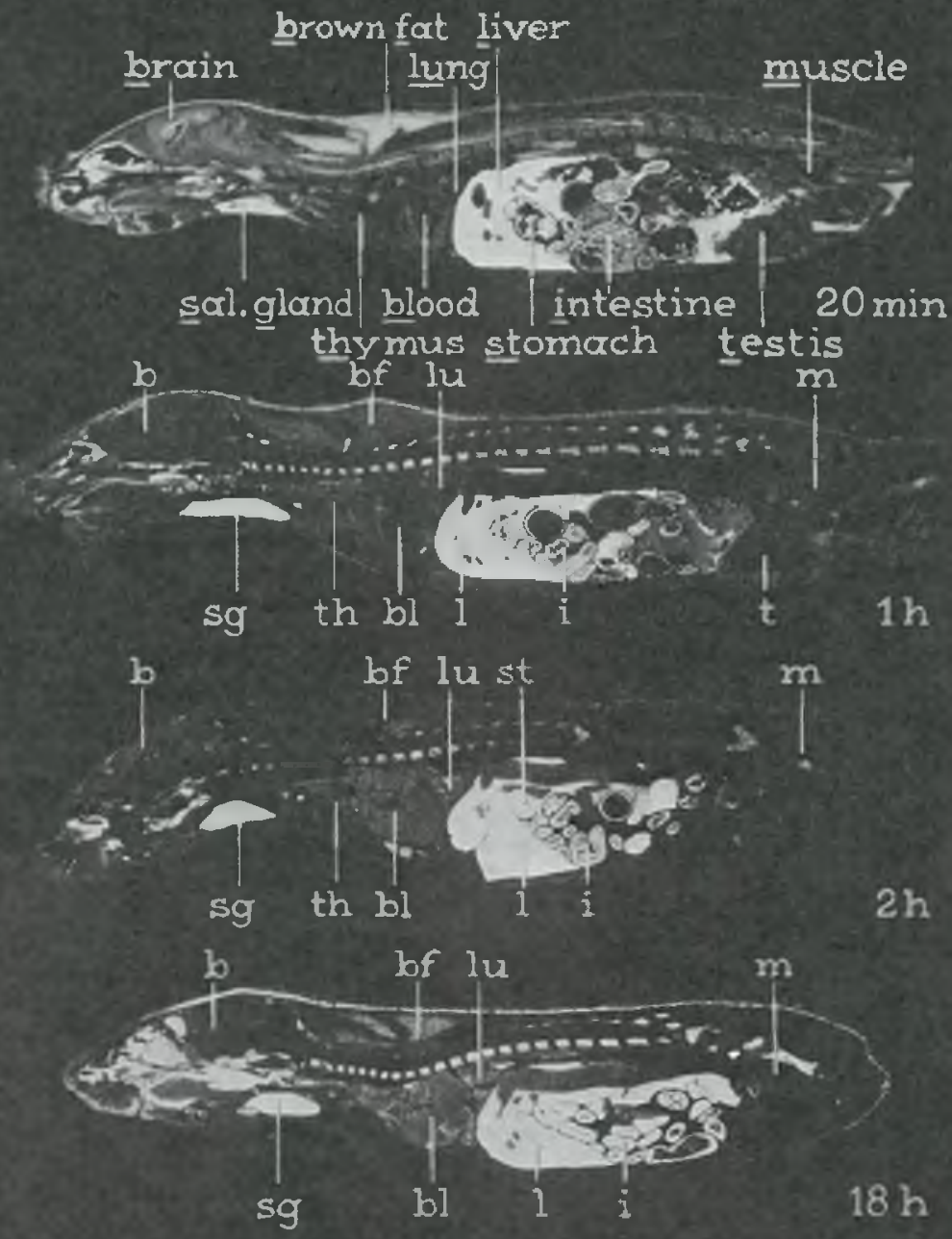

Fig. 3. Autoradiograms of diazepam- $-\mathrm{N}-14 \mathrm{CH}_{3}$ in mice during the period of 20 min.$18 \mathrm{hrs}$ after rapid intravenous administration. 


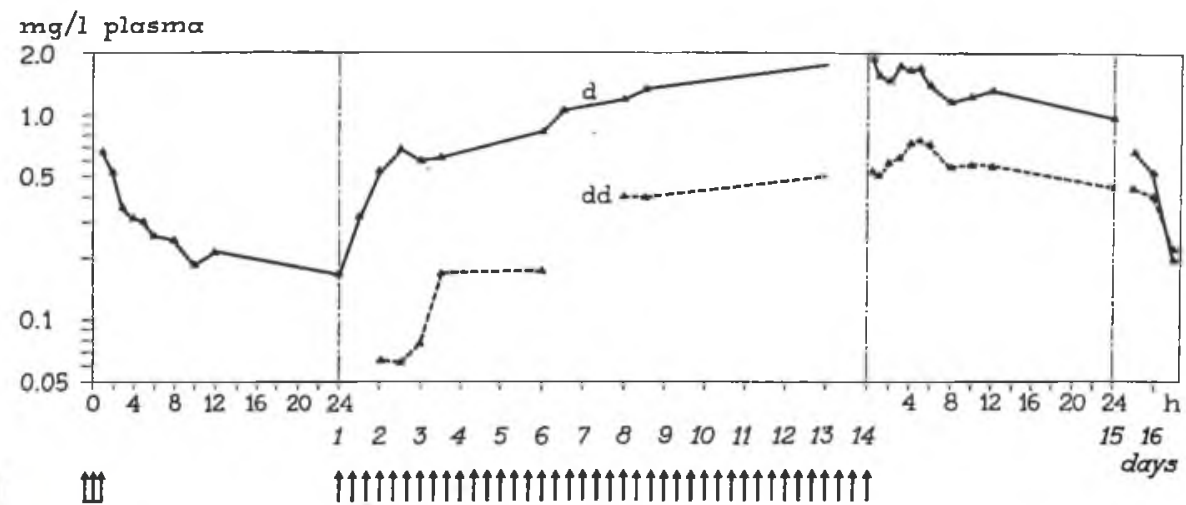

Fig. 4. Blood plasma concentration-time course of diazepam (D) and its metabolite desmethyldiazepam (DD) in a psychiatric patient after a single dose of $30 \mathrm{mg}$, during subchronic treatment with 3 times $10 \mathrm{mg}$ daily during 13 days and during subsequent 3 days following the treatment. Notice that the initial elimination pattern differs from the post treatment pattern (patient $\mathrm{dB}$ ).

tration show an erratic time course (fig. 5). The earlier shown rapid initial decay is no longer observed anymore. This can theoretically be expected as will presently be discussed. Within certain limitations a half-life of $24 \mathrm{hrs}$ for $\mathrm{D}$ can be estimated in patient d B.

The concentration time curves represented in fig. 6 show the accumula-

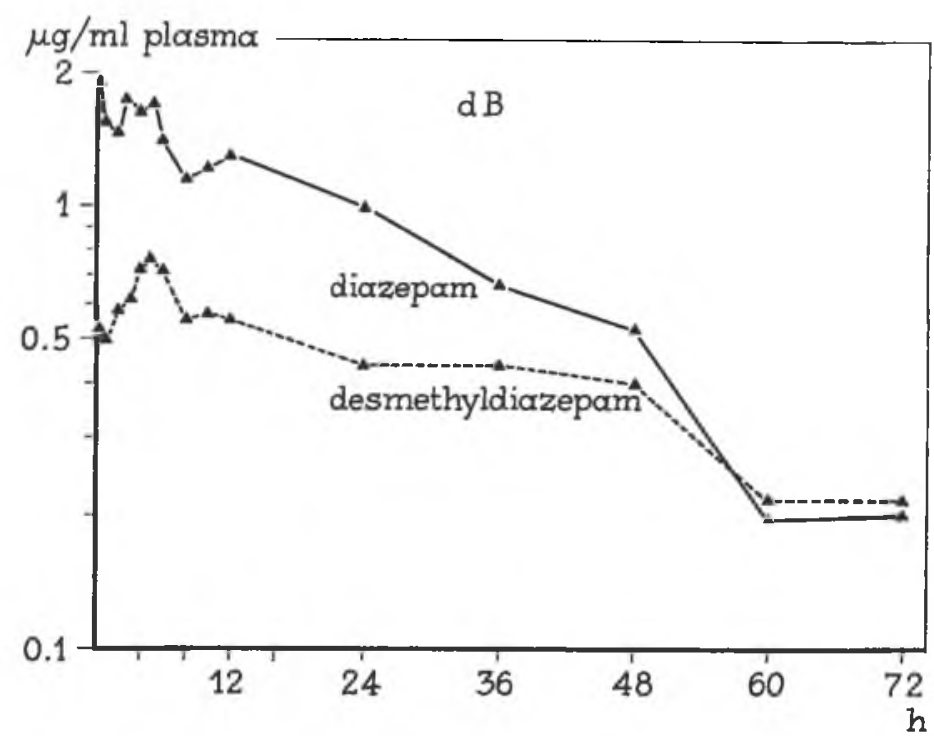

Fig. 5. Rescaled blood plasma concentration-time course of $\mathrm{D}$ and $\mathrm{DD}$ during the post subchronic treatment period presented in fig. 4. Notice that during the initial decay an erratic course is shown of both $\mathrm{D}$ and $\mathrm{DD}$. 


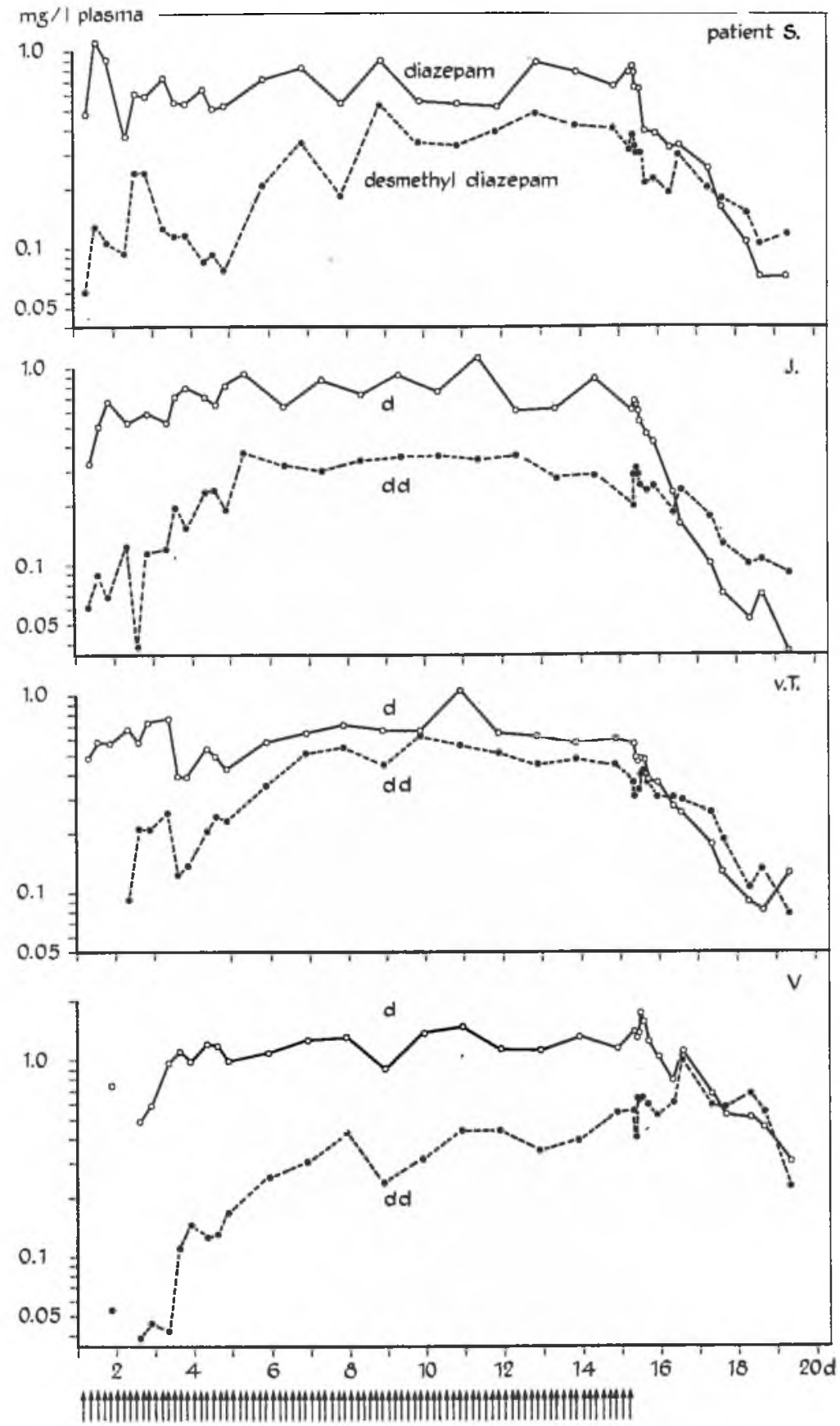

Fig. 6. Plasma concentration-time course of $D$ and $D D$ in four psychiatric patients during subchronic treatment with 3 times $10 \mathrm{mg} D$ daily over 15 days and the subsequent 4 days following the treatment. 

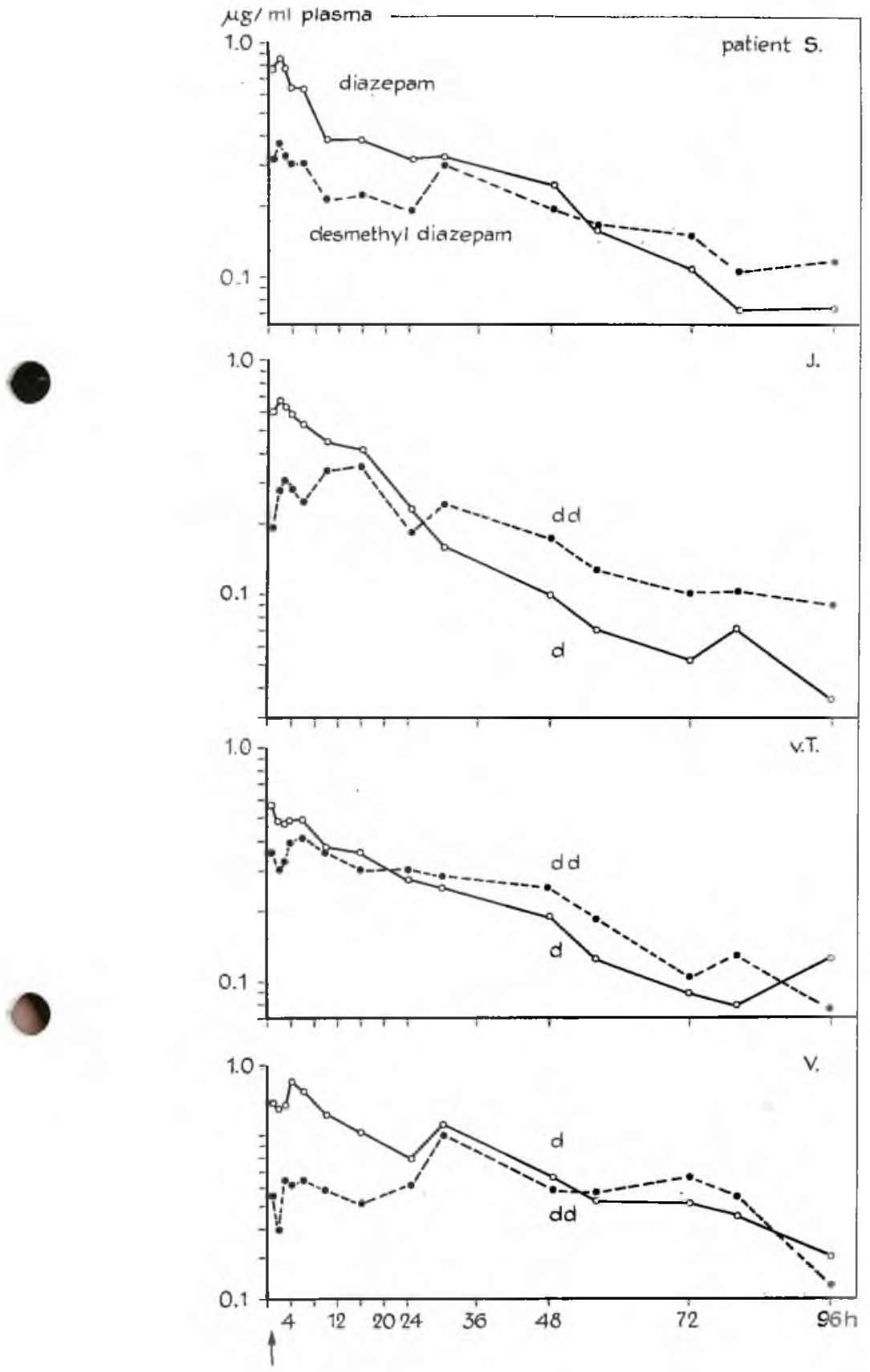

Fig. 7. Rescaled blood plasma concentration-time course of $\mathrm{D}$ and $\mathrm{DD}$ during the post treatment period in the four patients represented in fig. 6. 
Table 1.

$\overline{\mathrm{C}}_{\mathrm{pl}}=$ average blood plasma concentration at the steady state plateau level $(\mathrm{mg} / 1)$. Subscriptions $\mathrm{D}$ and $\mathrm{DD}=$ diazepam and desmethyldiazepam

$\mathrm{t}$

$\mathbf{k}_{12}=$ rate of elimination of diazepam $\left(\mathrm{hr}^{-1}\right)$

$\mathbf{k}_{23}=$ rate of elimination of desmethyldiazepam $\left(\mathrm{hr}^{-1}\right)$

M Clearance = metabolic clearance; the volume of the apparent steady-state volume of distribution cleared per unit of time $(1 / \mathrm{hr})$

\begin{tabular}{|c|c|c|c|c|c|c|c|}
\hline Patient & $\begin{array}{l}\text { Dose } \\
\text { (mg) }\end{array}$ & $\begin{array}{l}\text { Interval } \\
\text { (hr) }\end{array}$ & $\overline{\mathrm{C}}_{\mathrm{Dpl}}$ & $\overline{\mathrm{C}}_{\mathrm{DDpl}}$ & t t $\frac{1}{2}$ & $\mathrm{t}_{2}^{\frac{1}{2} \mathrm{DD}^{*}}$ & $\begin{array}{c}\text { Body } \\
\text { weight } \\
\text { (kg) }\end{array}$ \\
\hline d B & 10 & 8 & 1.50 & 0.40 & 24 & 48 & 95 \\
\hline $\mathbf{s}$ & 10 & 8 & 0.80 & 0.43 & 24 & 56 & 68 \\
\hline $\mathbf{J}$ & 10 & 8 & 0.85 & 0.35 & 20 & 42 & 60 \\
\hline v T & 10 & 8 & 0.70 & 0.52 & 30 & 44 & 80 \\
\hline \multirow[t]{2}{*}{ V } & 10 & 8 & 1.30 & 0.46 & 42 & 96 & 78.5 \\
\hline & $\mathbf{k}_{12}$ & $\mathrm{k}_{83} *$ & $\mathbf{k}_{23} * *$ & $\mathrm{t} \frac{1}{2} \mathrm{DD}^{* *}$ & $\begin{array}{c}\mathbf{M} \\
\text { Clear- } \\
\text { ance }\end{array}$ & $V_{D}$ & $\underset{\%}{\triangle \mathrm{BW}}$ \\
\hline d B & $28.8 \times 10^{-3}$ & $14.1 \times 10^{-3}$ & $108.0 \times 10^{-3}$ & 6.4 & 0.833 & 28.9 & 30 \\
\hline $\mathbf{S}$ & $28.8 \times 10^{-3}$ & $12.3 \times 10^{-3}$ & $53.6 \times 10^{-3}$ & 12.9 & 1.563 & 54.3 & 77 \\
\hline J & $34.7 \times 10^{-3}$ & $16.5 \times 10^{-3}$ & $84.3 \times 10^{-3}$ & 8.2 & 1.471 & 42.4 & 77 \\
\hline $\mathbf{v T}$ & $23.1 \times 10^{-3}$ & $15.7 \times 10^{-3}$ & $31.1 \times 10^{-3}$ & 22.3 & 1.786 & 77.3 & 96.5 \\
\hline V & $16.4 \times 10^{-3}$ & $7.2 \times 10^{-3}$ & $46.3 \times 10^{-3}$ & 15.0 & 0.962 & 58.7 & 74 \\
\hline
\end{tabular}

$\mathrm{V}=$ apparent volume of distribution at the steady-state (1).

$\triangle \mathrm{BW}=$ fraction of bodyweight taken by $\mathrm{V}$.

- This value has been determined from the tangent of the post treatment curve.

* This value has been determined with the aid of eq. 12 .

tion patterns of $\mathrm{D}$ and $\mathrm{DD}$ during subchronic treatment with 3 divided doses of $10 \mathrm{mg}$ daily and the post treatment course. In fig. 7 the time basis is rescaled allowing a better picture of the elimination pattern. The pharmacokinetic parameters that can be obtained from this post treatment curve also suffer from inaccuracy. An estimate of the biological half-life of the drug in humans is made in table 1. Estimation of the half-life of DD that has qualitatively a similar but quantitatively a slightly lower pharmacological activity (RANDALL et al. 1965) has theoretical and practical implications that will be described in the discussion.

Plasma protein binding of $\mathrm{D}$ has been determined to be virtually linear over the therapeutic concentration range (fig. 8).

A protein binding capacity of $96 \%$ has been calculated. 


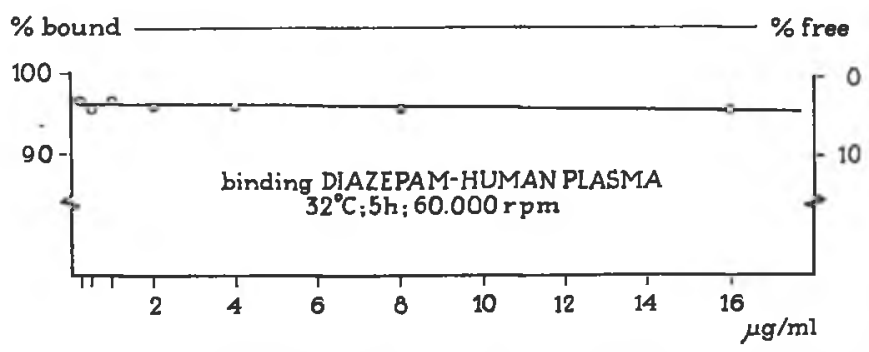

Fig. 8. Blood plasma protein binding capacity of diazepam in human plasma, at $70,000 \mathrm{rpm}$.

\section{Discussion}

There are two basic questions that have to be considered for every drug and individual before one can depend on pharmacokinetic parameters calculated from plasma concentrations to predict or correct dosage regimens.

First, what is the relation between the concentration in the body fluid where the drug can be assayed and the concentration in the organ, tissue or humour where the drug will demonstrate its activity? Second, what is the relevance of a peripheral or regional concentration for the nature and intensity of the action?

The first question may be answered by the use of mathematical models commonly used in pharmacokinetics. The principle on which pharmacokinetics operate is that the relationship between the concentration of the drug in one body and the concentration in one or more peripheral bodyfluids can be expressed in mathematical terms. In many cases an excellent fit of data has been obtained assuming one, two or three mathematical compartments and first order mass transfer. To extend the meaning of these abstract compartments there is a tendency to identify them with anatomical or physiological regions and spaces. This appears only to be valid in a restricted number of compounds e.g. iodine albumine, inuline, antipyrine etc.

The value of this approach largely depends on the accuracy, the specificity of the assay, the connected detection range and the sampling protocol. These factors will determine, whether or not the different compartments can be distinguished.

For many drugs the hypothetical peripheral compartments may indeed show the postulated homogeneity.

However, many other drugs show selective tissue affinity, that mathematically moreover will often be of a non-linear type. In humans it is practically impossible to estimate a peripheral drug concentration and 
much of our knowledge is based on animal experiments. But here too, technical improvements have to be made in order to detect these relations between the plasma and the receptor or "molecular" level.

Because of the anticipated difficulties after a single dose where distribution, elimination with linear and non-linear kinetics can complicate the patterns in the different compartments, it is often more simple to study the plasma concentration-pharmacological activity relationship at the steady state level of the drug. However it can be very difficult to establish the same clear multi steady state level-pharmacological response relationship as have succesfully been found in isolated organ experiments (ARIËNs et al. 1964).

When biological half-life and dosage interval allow only negligible concentration fluctuations and when absorption is relatively rapid and complete,

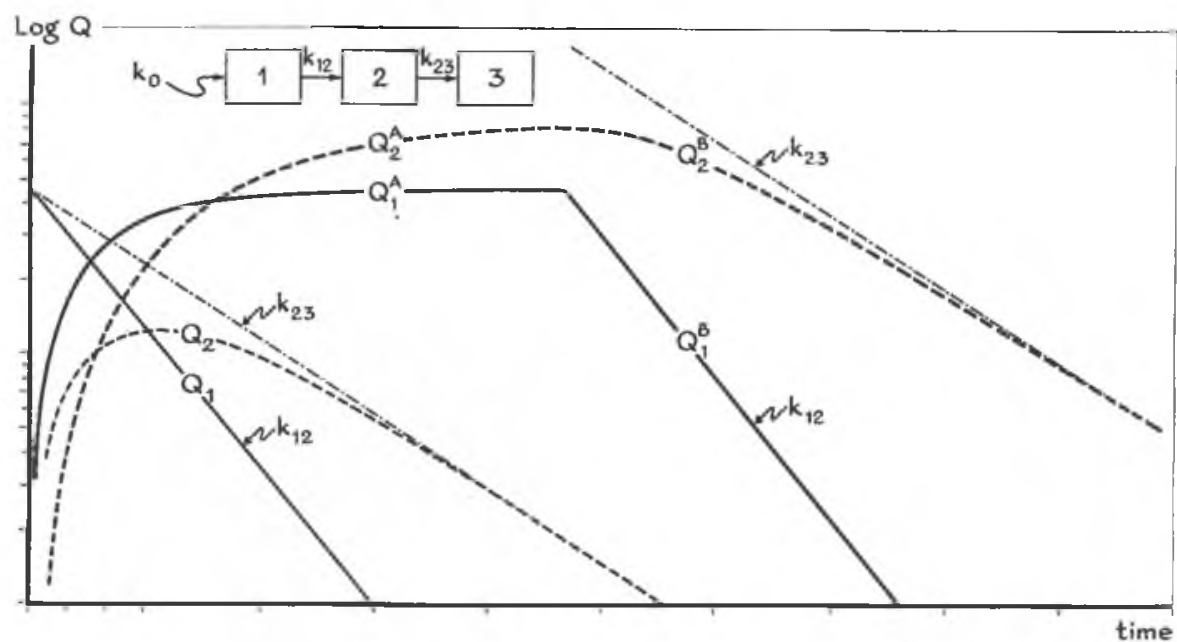

Fig. 9, insertion. Schematic representation of a catenary chain system with zero order infusion $\left(k_{0}\right)$ into compartment 1 . The rate constants representing the mass transfer between the compartments are considered to be of the first order type. The drug as well as the metabolites 2 and 3 are supposed to be distributed in one compartment. Fig. 9. Theoretical amount-time curves after a single dose of drug, of its metabolite, during linear infusion and following the infusion period. For the sake of a clear illustration the elimination of the drug is 2 times faster than of the metabolite, this in contrast with most of the observations with $\mathrm{D}$ and $\mathrm{DD}$ in humans. $\mathrm{k}_{0}=0.45$ unit weight/time; $k_{12}=0.9$ time $^{-1} ; k_{23}=0.45$ time $^{-1}$. $Q_{1}$ and $Q_{2}$ are the amounts of drug and of metabolite after a single dose of $Q=0.45$ unit weight. The subscriptions $A$ and $B$ indicate the infusion - and the post infusion period respectively. When both drug and metabolite are pharmacologically active, then the elimination of the active moiety is slower than of the parent compound even when the metabolite is eliminated more rapidly. 
then apparent linear zero order infusion kinetics can be applied to describe the accumulation of the drug and metabolites in plasma.

The theoretical aspects of linear infusion have recently been reviewed by GIBALDI (1969) and in a more general form by LOO \& RIEGELMAN (1970). From their work it becomes clear that since accumulation takes place it will technically be easier to decide on the kinetic characteristics of a drug. It also explains that when there are relatively large differences between the rate constants in e.g. a two compartment model it becomes more difficult to distinguish the two phases of the post infusion plasma curves as the time of infusion is increased.

This can also explain the change in half-life of tetracyclines (DoLUisio \& DITTERT 1969) during subchronic treatment where an initially unobserved slower elimination phase may control the post steady state curve. This explanation is also valid for the difference in apparent elimination rate of diazepam after a single dose and after subchronic treatment (fig. 4).

The concentration pattern as reported in fig. 6 may be treated in a simple catenary chain system for the precursor-product relationship, according to the insertion in fig. 9, assuming a one compartment model (1) for the drug (D) with zero order infusion with rate $\mathrm{k}_{0}(\mathrm{mg} / \mathrm{hr})$ and one compartment (2) for the metabolite (DD).

In the case of diazepam both the parent compound $\mathrm{D}$ and $\mathrm{DD}$ are completely eliminated by metabolism since no intact material has been found in urine or faeces.

The mathematical equations have been derived by RESIGNo \& SEGRE (1966) and WAGNER (1969).

$\mathrm{Q}_{\mathrm{A}}=\left(\mathrm{k}_{0} / \mathrm{k}_{12}\right) \cdot\left(1-\mathrm{e}^{--\mathrm{k}_{12} \mathrm{t}}\right)$

$\mathrm{Q}_{\mathrm{A}}^{2}=\left(\mathrm{k}_{\mathrm{o}} / \mathrm{k}_{128}\right) \cdot\left[1+\left(\mathrm{k}_{23} \mathrm{e}^{-\mathrm{k}_{12} \mathrm{t}}-\mathbf{k}_{12} \mathrm{e}^{-\mathrm{k}_{28} \mathrm{t}}\right) /\left(\mathrm{k}_{12}-\mathrm{k}_{23}\right)\right]$

$\mathrm{Q}_{\mathrm{A}}^{3}=\mathrm{k}_{\mathrm{o}}\left(\mathrm{k}_{12}-\mathrm{k}_{23}+1\right) /\left(\mathrm{k}_{12}-\mathrm{k}_{23}\right)$

$$
\left[\left(k_{12} / k_{23}\right) e^{-k_{28} t}-\left(k_{83} / 12\right) e^{-k_{12} t}\right]
$$

When the linear infusion is stopped at time $t=t^{1}$ and the quantity of the drug if followed during time $t-t^{1}=t^{11}$ then the following set of equations apply:

$$
\begin{aligned}
\mathrm{Q}^{1}= & \left(\mathrm{k}_{\mathrm{o}} / \mathrm{k}_{12}\right) \cdot\left(1-\mathrm{e}^{-\mathrm{k}_{12} \mathrm{t}^{1}}\right) \cdot \mathrm{e}^{-\mathrm{k}_{12} \mathrm{t}^{11}} \\
\mathrm{Q}^{2}= & \left(\mathrm{k}_{\mathrm{o}} / \mathrm{k}_{12}\right) \cdot\left(1-\mathrm{e}^{-\mathrm{k}_{12} \mathrm{t}^{1}}\right) \cdot\left[\mathrm{k}_{12} /\left(\mathrm{k}_{23}-\mathrm{k}_{12}\right)\right] \cdot\left(\mathrm{e}^{-\mathrm{k}_{12} \mathrm{t}^{11}}-\mathrm{e}^{-\mathrm{k}_{2 \mathrm{~g}} \mathrm{t}^{11}}\right)+ \\
& \left(\mathrm{k}_{\mathrm{o}} / \mathrm{k}_{29}\right) \cdot\left[1+1 /\left(\mathrm{k}_{12}-\mathrm{k}_{29}\right)\left(\mathrm{k}_{23} \mathrm{e}^{-\mathrm{k}_{12} \mathrm{t}^{11}}-\mathrm{k}_{12} \mathrm{e}^{\left.-\mathrm{k}_{29} \mathrm{t}^{1}\right)}\right) \cdot \mathrm{e}^{-\mathrm{k}_{29} \mathrm{t}^{11}}\right.
\end{aligned}
$$




$$
\mathrm{Q}^{3} \mathrm{~B}=\mathrm{k}_{23} \int_{\mathrm{t}^{1}}^{\mathrm{t}^{11}} \mathrm{Q}_{2}^{\mathrm{B}} \mathrm{dt}
$$

When the infusion time $t^{1}$ is great, then equations 4 and 5 can be simplified to

$$
\begin{aligned}
& \mathrm{Q}^{1}{ }_{\mathrm{B}}=\left(\mathrm{k}_{\mathrm{o}} / \mathrm{k}_{12}\right) \mathrm{e}^{-\mathrm{k}_{12} \mathrm{t}^{11}} \\
& \mathrm{Q}^{2}{ }_{\mathrm{B}}=\left(\mathrm{k}_{\mathrm{o}} / \mathrm{k}_{29}\right) \mathrm{e}^{-\mathrm{k}_{23}{ }^{t^{11}}}+\left[\mathrm{k}_{0} /\left(\mathrm{k}_{23}-\mathrm{k}_{12}\right)\right]\left(\mathrm{e}^{-\mathrm{k}_{12} t^{11}}-\mathrm{e}^{-\mathrm{k}_{28} \mathrm{t}^{11}}\right)
\end{aligned}
$$

Since the amount excreted $\left(\mathrm{Q}^{3}\right)$ has not been assayed in this study it will not be considered further.

$$
\begin{aligned}
& \text { At } \mathrm{t}^{11}=0: \\
& \mathrm{Q}^{1}{ }_{\mathrm{B}}=\mathrm{k}_{0} / \mathrm{k}_{12} \\
& \text { and } \\
& \mathrm{Q}^{2_{\mathrm{B}}}=\mathrm{k}_{0} / \mathrm{k}_{23}
\end{aligned}
$$

In these equations $Q$ is quantity of the drug, the superscriptions 1,2 and 3 refer to the compartments. Subscriptions A and B refer to the infusion and post infusion period respectively, $\mathbf{k}$ stands for the first order rate constant $\left(\mathrm{hrs}^{-1}\right)$, the subscriptions indicate the direction of the mass transfer, and $\mathrm{t}$ is the time after starting the infusion. Also

$\mathrm{Q}=\mathrm{C} . \mathrm{V}$.

where $\mathrm{C}$ is the concentration and $\mathrm{V}$ is the apparent distribution volume at the steady-state.

When we, with all reserves, assume the same distribution volume for $Q_{1}$ and $\mathrm{Q}_{2}$ then $\mathrm{k}_{23}$ can be calculated from the ratio of the steady-state plasma concentrations, when $k_{12}$ is determined from the post treatment curve.

$$
\frac{\mathrm{C}^{1}}{\mathrm{C}^{2}}=\frac{\mathrm{k}_{22}}{\mathrm{k}_{12}}=\frac{\mathrm{t}^{\frac{1}{2}} \mathrm{D}}{\mathrm{t}^{\frac{1}{2}} \mathrm{DD}}
$$

The assumption of equal volumes for parent compound and metabolite is arbitrary. Only studies under equal conditions with the metabolite given as parent compound can solve this problem.

The post treatment or post infusion curve of the drug does not allow an accurate estimate of the rate of elimination of the metabolite. The course of the curve of the metabolite (2) is determined by two terms (eq.8). The second part approaches more rapid to zero than the first part of the righthand side of the equation. So theoretically only the tangent to the curve will give the $k_{23}$ value (fig. 9). 
A large discrepancy can be noted between the value of $\mathrm{k}_{23}$ calculated from the steady-state concentrations and that determined from the tangent of the post treatment curve (table 1). Desmethyldiazepam has qualitatively a similar but quantitatively a slightly lower pharmacological activity in animals (RANDALL et al. 1965; MARCUCCI et al. 1968). If this can be translated to man then it is not the intrinsic elimination rate of $\mathrm{DD}\left(\mathrm{k}_{23}\right)$ but the more complex function (eq.8) that has to be considered in the additive relation with the pharmacological activity.

The catenary infusion model serves as a simplified scheme for the chronic treatment of drugs in humans. A two or more compartment model for the drug may be masked by the long treatment and the erratic concentration pattern, for which individual enteral reasons are suggested. When we assume that the absorption is relatively rapid and complete and that the half-life of the compound is large compared to the dosage interval and thus $k_{0}=Q / \triangle t$ then eq. 9 can be rewritten as the equation given by WAGNER et al. (1965) and by VAN ROSSUM AND TOMEY (1968):

$\overline{\mathrm{C}_{\mathrm{pl}}}=1.44 \mathrm{Q} \cdot \mathrm{t}_{\frac{1}{2}} / \Delta \mathrm{t} . \mathrm{V}$

since $1 / \mathrm{k}=1.44 \mathrm{t}_{\frac{1}{2}}$

where $\mathrm{Q}$ is the dose, $\Delta \mathrm{t}$ is the dosage interval and where $\overline{\mathrm{C}_{\mathrm{pl}}}$ is the average plasma plateau concentration. This equation allows the calculation of the apparent distribution volume (V) of the subjects. The relative large individual differences have been reported in table 1 .

As a consequence of the accumulation and addition of the metabolite, a higher concentration of the active substances in the brain and a longer time course of action are anticipated after subchronic treatment. However, clinical observation does not reveal an extension of the activity compared with the single dose treatment. Defined pharmacological criteria are necessary to allow a conclusion to this.

This brings up the second question initially mentioned in this discussion about the relevance of a regional drug concentration for the pharmacological activity.

Earlier experiments in mice have demonstrated that diazepam is extensively and rapidly taken up in the brain and in the bodyfat and that metabolites of this drug are also rapidly appearing in the stomach contents, the bile and subsequently in the gastrointestinal tract after intravenous injection (VAN DER KLEIJN 1969a).

It is very likely that this enterohepatic and to a smaller extend enterogastric and enteroglandular cycling of e.g. the salivary glands and lachrymal glands and subsequent sustained reabsorption contribute to the erratic and 
extended concentration course of diazepam and likely other weakly basic compounds.

After an initial high uptake in the gray matter of the brain the drug and metabolites are rapidly redistributed into the fiber tracts of spinal cord, brain stem and the white matter of the cortex.

The gray matter of the limbic system has been recognized neurophysiologically as the site of action of diazepam and related antianxiety drugs (SCHALLEK et al. 1964).

It is not clear yet whether the presence in the white matter has any signifi-
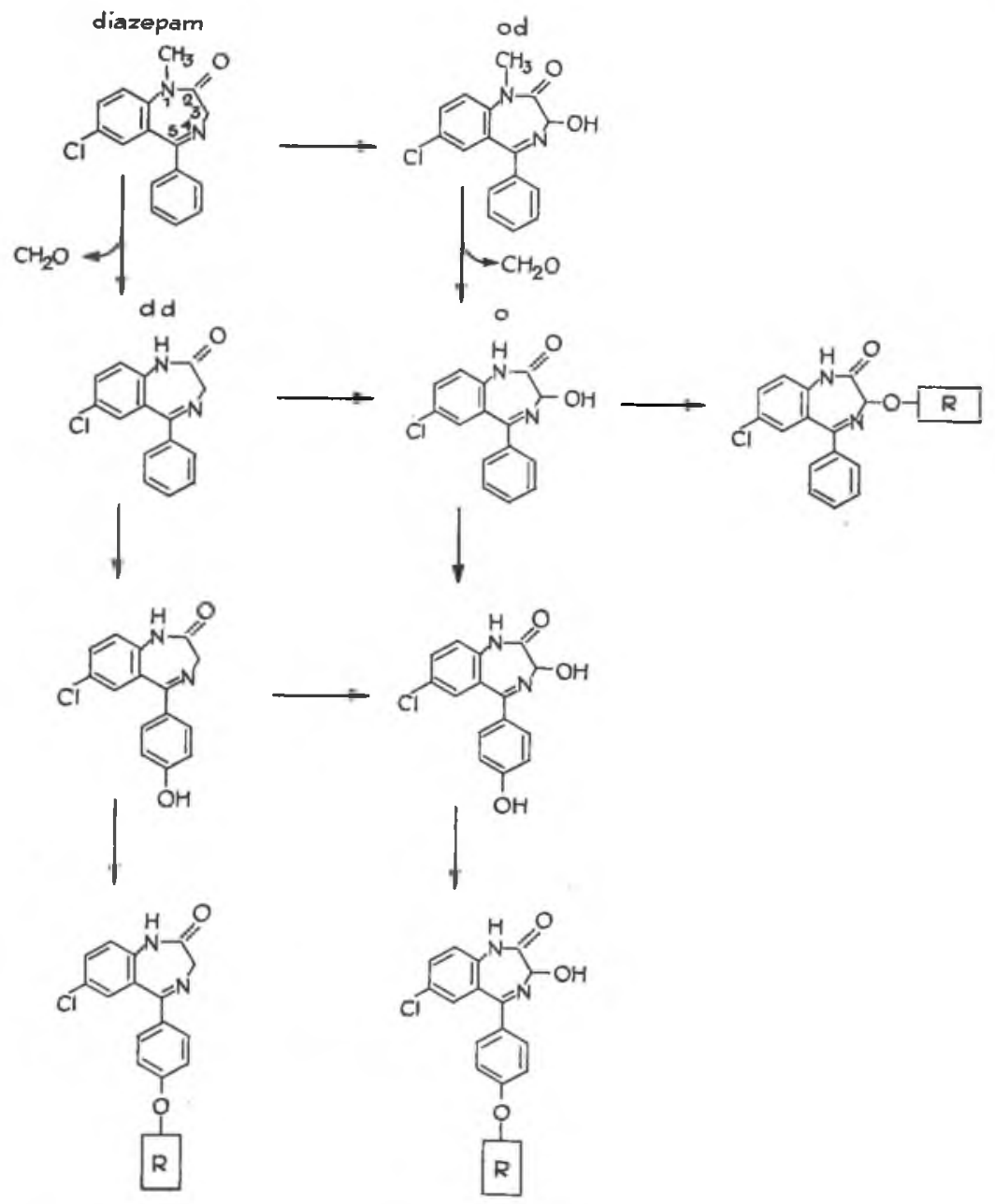

Fig. 10. Schematic representation of the metabolic pathways of diazepam. The abbreviations are explained under Methods. 
Table 2.

The columns 1, 2 and 3 refer to the different phases of the concentration-time curves.

Biological half-lives of diazepam and desmethyldiazepam in different species

\begin{tabular}{|c|c|c|c|c|c|c|c|c|c|}
\hline \multirow{2}{*}{ Species } & \multicolumn{3}{|c|}{$\mathrm{D}$} & \multirow{2}{*}{$\frac{\text { DD }}{3}$} & \multicolumn{2}{|c|}{ D-14C2 } & \multicolumn{3}{|c|}{$\mathrm{D}-\mathrm{N}_{1}-14 \mathrm{CH}_{3}$} \\
\hline & 1 & 2 & 3 & & 2 & 3 & 1 & 2 & 3 \\
\hline Mouse & $4 \frac{1}{2} \mathrm{mi}$ & $40 \mathrm{~min}$. & & $>4 \mathrm{hrs}$ & & $>4 \mathrm{hrs}$ & & & \\
\hline Dog & $4 \mathrm{mi}$ & $40 \mathrm{~min}$. & 9 hrs & $9 \mathrm{hrs}$ & $3 \mathrm{hrs}$ & $16 \mathrm{hrs}$ & $4 \frac{1}{2} \mathrm{~min}$. & $80 \mathrm{~min}$. & $100 \mathrm{hrs}$ \\
\hline Human & & & $\begin{array}{c}24-42 \\
\text { hrs }\end{array}$ & & & & & & \\
\hline
\end{tabular}

* Data from VAN DER KLEIJN (1969a) derived from the heart tissue concentrations.

cance for the different shades in pharmacological activity and time course of action. The longest retention of the radioactivity in mice is observed in the liver, gastrointestinal tract, bone marrow, skin and salivary and lachrymal glands (fig. 3).

The metabolism of diazepam has been found possibly to occur along the scheme given in fig. 8 (SchwarTz et al. 1965; SchwarTz et al. 1967). Oxydiazepam and oxazepam however are only uncommonly found in human plasma.

The studies in dogs and mice using radio labelled drug indicate that other metabolites that have not been assayed by the gas chromatographic method must be present (fig. 1, VAN DER KLEIJN 1969c). So far no qualitative and quantitative data on the chemical or pharmacological nature of these compounds in men are present.

Theoretically the $\mathrm{D} \rightarrow \mathrm{OD} \rightarrow \mathrm{O} \rightarrow \mathrm{O}$-glucuronide pathway could be very rapid. The step from DD to $O$ could be rate limiting and thus be responsible for the accumulation of DD in plasma. A definitive answer to this problem again can only be given by studies with these metabolites given as parent compound to the same subjects.

The differences and similarities in the kinetics reflecting mixing (1), distribution (2) and elimination (3) of drug and metabolite in three species are shown in table 2 .

The extremely slow elimination of the total radioactivity originating from D- $\mathrm{N}_{1}{ }^{14} \mathrm{CH}_{3}$ in the dog and the increasing protein binding capacity as can be concluded from the different slopes of the curves for plasma and plasma water indicates that the arisen $-{ }^{14} \mathrm{CH}_{3}-$ group is taken up by the plasma proteins to a large extend. 
Plasma protein binding has been demonstrated to influence the pharmacokinetics of elimination for those drugs where it potentially controls the gradient over membranes (ANTON 1961). However, for the more lipophylic compounds that rapidly penetrate intracellularly the effect of the, by the binding decreased, gradient is effectively compensated (VAN DER KLEIJN 1969b).

\section{Summary}

Distribution in mice shows that diazepam is rapidly taken up in the brain, but that it is also rapidly eliminated there and slower from the body fat. Retention of radioactivity can be observed in the gastrointestinal tract and the excretory organs. The studies in dogs show that the drug is also rapidly metabolized resulting in identified and unidentified metabolites some of them having a longer biological half-life.

Blood plasma concentrations of drug and metabolite have been followed during single dose, subchronic and post subchronic treatment with diazepam in psychiatric patients. The accumulation of metabolites in the gastrointestinal tract as observed in animal studies after intravenous administration is suggested to influence the kinetics of absorption and reabsorption together with environmental factors.

\section{Acknowledgements}

This study has been supported by the Dutch Organization for Purely Scientific Research and the Dr. Saal van Zwanenberg Foundation. The authors acknowledge the cooperation of Drs. G. P. J. A. van Lier, Psychiatric Center "St. Servatius", Venray, and G. C. de Ruyter de Wildt, Psychiatric Hospital "Brinkgreven", Deventer, the Netherlands, who conducted the clinical studies. Dr. H. Kaegi of Hoffmann-La Roche Inc., Nutley, N. J., U.S.A. is thanked for the supply of the diazepam $-\mathrm{N}_{1}-{ }^{14} \mathrm{CH}_{3}$.

\section{REFERENCES}

Anton, A. H.: A drug induced change in the distribution and renal excretion of sulfonamides. J. Pharmacol. 1961, 134, 291-303.

Ariëns, E. J., A. M. Simonis \& J. M. van Rossum: Molecular pharmacology. Ed.: E. J. Ariëns. Academic Press, New York and London, 1964, 1, 119.

De Silva, J. A. F., B. A. Koechlin \& G. Bader: Bloodlevel distribution patterns of diazepam and its major metabolite in man. J. Pharm. Sci. 1966, 55, 692-702.

Doluisio, J. T. \& L. W. Dittert: Influence of repetitive dosing of tetracyclines on biologic half-life in serum. Clin. Pharmacol. Therap. 1969, 10, 690-701.

Gibaldi, M.: Estimation of the pharmacokinetic parameters of the two-compartment open model from post infusion plasma concentration data. J. Pharm. Sci. 1969, 58, 1133-1135. 
Jelliffe, R. W.: A mathematical analysis of digitalis kinetics in patients with normal and reduced renal function. Math. Biosci. 1967, 1, 305-325.

Krüger Thiemer, E. \& P. Bünger: The role of the therapeutic regimen in dosage design (part I and II). Chemotherapia 1965, 10, 61-73.

Krüger Thiemer, E. \& P. Bünger: The role of the therapeutic regimen in dosage design part I and II). Chemotherapia 1966, 10, 129-144.

Loo, J. C. K. \& S. Riegelman: Assessment of pharmacokinetic constants from post infusion blood curves obtained after i.v. infusion. J. Pharm. Sci. 1970, 59, 53-55.

Marcucci, F., A. Guaitani, J. Kvetina, E. Mussini \& S. Garatinni: Species differences in diazepam metabolism and anticonvulsant effect. Eur. J. Pharmacol. 1968, 4, 467-470.

Marcucci, F., R. Fanelli \& E. Mussini: A method for gaschromatographic determination of benzodiazepines. J. Chromatogr. 1968, 37, 318-320.

Randall, L. O., C. L. Scheckel \& R. F. Banzinger: Pharmacology of the metabolites of chlordiazepoxide and diazepam. Curr. Therap. Res. 1965, 7, 590-606.

Resigno, A. \& G. Serge: Drug and tracer kinetics. Blaisdell, New York, N.Y., 1966, $29-40$.

Schallek, W., F. Zabransky \& A. Kuehn: Effect of benzodiazepines on central nervous system of cat. Arch. Int. Pharmacodyn. 1964, 149, 467-483.

Schwartz, M. A., B. A. Koechlin, E. Postma, S. Palmer \& G. Krol: Metabolism of diazepam in rat, dog and man. J. Pharmacol. 1965, 149, 423-435.

Schwartz, M. A., P. Bommer \& F. M. Vane: Diazepam metabolites in the rat, Arch. Biochem. Biophys. 1967, 121, 508-516.

Ullberg, S.: Studies on the distribution an fate of S35-labeled benzylpenicillin in the body. Acta Radiol. 1954, suppl. 118, 22-31.

Van der Kleijn, E.: Kinetics of distribution and metabolism of diazepam and chlordiazepoxide in mice. Arch. Int. Pharmacodyn. 1969a, 178, 193-215.

Van der Kleijn, E.: Protein binding and lipophylic nature of ataractics of the meprobamate- and diazepine group. Arch. Int. Pharmacodyn. 1969b, 179, 225-250.

Van der Kleijn, E.: Pharmacokinetics of ataractic drugs. Thesis University of Nijmegen, Ste Catharina Press, Bruges, Belgium, 1969c.

Van Rossum, J. M. \& A. H. M. Tomey: Rate of accumulation and plateau concentration of drug after chronic medication. J. Pharm. Pharmacol. 1968, 20, 390-392.

Wagner, J. G., J. I. Northam, C. D. Alway \& O. S. Carpenter: Bloodlevels of drug at the equilibrium state after multiple dosing. Nature 1965, 207, 1301-1302.

Wagner, J. G.: Pharmacokinetics. J. M. Richards, Publisher, Grosse Point Park, Michigan, 1969. 